\title{
Review of Negative Impact of Extreme Temperature Elevations on Plant Growth, Development and Crop Yield using Mathematical Equations
}

\author{
Paul O. Jaiyeola, Funmilola A. Oluwafemi, Abdullahi Ayegba, Irene E. Benibo
}

\begin{abstract}
This study reviewed the negative impact of extreme temperature elevations on plant growth, development and crop yield using some mathematical equations that relates temperature either directly or indirectly with some agricultural parameters. The agricultural parameters employed are Temperature, Vapor Pressure Deficit (VPD), Transpiration, Leaf Water Potential, Stomatal Conductance, Photosynthesis, Carbon Dioxide $\left(\mathrm{CO}_{2}\right)$ Concentration, Substrate, Rubisco Activase/Activity, Electron Transportation and Cuticle Resistance. Ideally increasing temperature enhances transpiration and photosynthesis, but transpiration enhancement leads to leaf water loss and consequently to impaired Leaf Water Potential due to leaf water stress as transpiration increases with temperature. The decreased Leaf Water Potential results in a reduced stomata opening and Stomatal Conductance. Increasing VPD as temperature increases also reduce Stomatal Conductance. This stomatal closure or reduced Stomatal Conductance enhances $\mathrm{CO}_{2}$ concentration on the leaf surface and intercellular system of the leaf which further causes reduction in Stomatal Conductance. The enhancement of $\mathrm{CO}_{2}$ concentration on/in the leaf promotes greenhouse gases effect leading to leaf temperature enhancement. The increase in the $\mathrm{CO}_{2}$ concentration accumulated on the leaf leads to impairment of Rubisco activity due to decrease in $\mathrm{CO}_{2}$ assimilation, because the transpiration rate is not matching with the incoming $\mathrm{CO}_{2}$ or the photosynthetic rate due to the leaf water stress, as transpiration increases with temperature. The excess $\mathrm{CO}_{2}$ found accumulating on and inside the leaf further reduce Stomatal Conductance, enhance leaf temperature and lowdown the electron transportation to reduce the Rubisco activase/activity that determine photosynthetic rate as temperature increases. It was discovered that increasing VPD as well as increasing $\mathrm{CO}_{2}$ decreased Stomatal Conductance, having direct negative effect on Stomatal Conductance than temperature elevations. Increasing $\mathrm{CO}_{2}$ concentration accumulated on the leaf with decrease in electron transportation decreases Rubisco activity that is meant to enhance photosynthesis as temperature increases. Increase in VPD and increase in $\mathrm{CO}_{2}$ concentration on and inside the leaf, with the decrease in Leaf Water Potential can be seen as the direct and best factors that majorly influence Stomatal Conductance rather than increasing temperature that has indirect influence. The increase in Stomatal Resistance, decrease in Stomatal Conductance, decrease in electron transportation and increased $\mathrm{CO}_{2}$ will in turn impair transpiration and photosynthetic rate (or Rubisco activity) which consequently leads to poor plant growth, development and most especially crop yield.
\end{abstract}

KEYWORDS: Temperature, Transpiration, Stomatal Conductance, Rubisco Activity.

\section{INTRODUCTION}

The principal object that normally caused changes in climate and weather of the earth is the Sun activities coupled with the earth's rotation about its own axis and its revolution around the earth. The Sun activities and earth's rotation and revolution can alter the earth's climate or weather parameters such as temperature, rainfall, relative humidity, pressure, wind speed and irradiance, which also have feedback on earth's weather and climate. Also, human activities such as production of greenhouse gases and depletion of ozone can affect planet earth climate or weather through global warming which is consequence of raising temperature due to greenhouse gases activities and ozone depletion. The impacts of changes in weather parameters have been discovered to impact alteration in plant growth, development and crop yield. Simple plant sustainability from seeding or planting is not independent of climate or weather parameters variability. Simply because cropping is practiced over wide range of agro-ecosystem, field crops being grown in climate - ranging from very hot to very cold, and from very wet to very dry, across temperate, tropical, and semi-arid zones; and that climate or weather variability is highly suitable for studying the major determinants of climate on crop productivity and climate is fundamental to crop growth (White and Mark, 2002). So, the more the relationships between crops and climate is understood, the better the stronger plan and design cropping practices that can be made (McKenzie, 2017). Basically, the plant development and growth sustainability depend solely on the interactive activities between various climate parameters from planting to harvesting. Germination is a miraculous event that involves a number of factors that include air (atmospheric air or wind), water (rainfall, moisture, precipitation and irrigation), light (sunlight or irradiation, sun intensity) and, of course, temperature (plant temperature, leaf temperature and air temperature) (Dyer, 2020). According to McKenzie (2017), crop growth and yield are strongly affected by sunlight, temperature and growing season precipitation and that farmer's perspective temperature and water availability are the two most important environmental factors that affect crop production.

Although temperature has been found to be a very important factors for plant growth and development; at the extreme end it has its own negative effect on plant growth. According to Hatfield and Prueger (2015), rates of plant growth and development depend upon the temperature surrounding the plant, and each species has a specific 
temperature range (i.e. extreme temperature affecting plant responses is species dependent) represented by a minimum, maximum, and optimum. Also, responses to temperature differ among crop species throughout their life cycle, and primarily the phonological responses i.e. the stages of plant development. For each species, a defined range of maximum and minimum temperatures form the boundaries of observation growth, while yield response to temperature varies among species based on the crop's cardinal temperature requirement. Warming temperature associated with climate change will affect plant growth and development along with crop yield, but beyond certain point, higher air temperature adversely affects plant growth, pollination and reproductive processes. Hatfield et al. (2015) reported further from their research that as air temperature rise beyond the optimum, instead of crop yield falling at a rate commensurate with the temperature increase, crop yield losses accelerate. Example, yield growth for corn, soybean, and cotton would gradually increase with temperature up to $29^{\circ} \mathrm{C}$ to $32^{\circ} \mathrm{C}$ and then sharply decrease with temperature increase beyond this threshold. Tomatoes, for example, get into trouble when temperatures exceed about $96^{\circ} \mathrm{F}\left(36^{\circ} \mathrm{C}\right)$. As stated, that the expectation of greater occurrence of temperature extremes will continue to have increasing negative impacts on plant production. Germination increases in higher temperatures up to a point and once the seeds reach optimum temperatures, which depends on the plant, germination begins to decline. Some plant seeds, including cool season vegetables, like lettuce and broccoli, germinate best in temperatures between 55 and $70^{\circ} \mathrm{F}\left(13\right.$ to $\left.21^{\circ} \mathrm{C}\right)$, while warm season plants, such as squash and marigolds, germinate best when temperatures are between 70 and $85^{\circ} \mathrm{F}$ $\left(21\right.$ to $13^{\circ} \mathrm{C}$ ). So, whether it's extreme heat or cold (Dyer, 2020), temperature variability effect on plant growth and development is also dependent upon plant species; some plants wilt when the mercury begins to increase, while others are at their best in extremes that would leave weaker plants begging for mercy. For example, cocoa is cultivated in areas having hot-humid climates, with average rainfall of between $1,150 \mathrm{~mm}$ and $2,500 \mathrm{~mm}$ and a temperature range of $18^{\circ} \mathrm{C}$ to $32^{\circ} \mathrm{C}$. Such areas lie along the equator in West Africa, Central and South America, and Asia (Ojo and Sadiq, 2010). High relative humidity $(>70 \%)$ is conducive to proliferation of black pod (Phytophthora palmivora) fungal diseases in cocoa. According to Osei (2017) in his research on cocoa yield in Ghana, cocoa is vulnerable to climate variability and it averagely thrives well within the temperature range of 18 to $21^{\circ} \mathrm{C}$ mean minimum and 30 to $32^{\circ} \mathrm{C}$ mean maximum, with rainfall average of $1500 \mathrm{~mm}$ to $2000 \mathrm{~mm}$ annually. This means that any increase or decrease below the mean minimum temperature or beyond the mean maximum temperature would negatively affect cocoa output, as well as, the application of some other determinants of cocoa output such as fertilizer and pesticides.

The most obvious effect is that of heat on photosynthesis and transpiration, and both processes increase as temperature increases but when temperature reach uncomfortable high limits (which depend on the plant), the two processes become unbalanced. The temperature at which most plant physiological processes are normally sustained ranges approximately from $0^{\circ} \mathrm{C}$ to $40^{\circ} \mathrm{C}$ and that very high and very low temperatures cause injury effects (Went, 1953). Effect of temperature on plants vary widely, and is influenced by factors such as exposure to sunlight, moisture drainage, elevation, difference between day and night temperatures, and proximity to surrounding rock structure (thermal heat mass). According to Powell et al. (2016) study at the global level, various weather scenarios were used to measure the effects of extreme weather events on agricultural regions with diverse crops, and it was found that higher temperature and events may lead to significant reduction in crop yields. According to Hatfield and Prueger (2015) temperature which would be considered extreme and fall below or above specific threshold at critical time during development can significantly impact productivity, and that extreme high temperature during reproductive stage will affect pollen viability, fertilization, and grain or fruit formation. Chronic exposures to extreme temperature during pollination stage of initial grain or fruit set will reduce yield potential, while acute exposure to extreme temperature events may be most detrimental during the reproductive stages of development. According to Rasul et al. (2011), day temperature in their optimum limit helps the photosynthetic process in the presence of sunlight while higher night temperature supports respiration process which is the reverse process of photosynthesis. Dry matter accumulation takes place when photosynthesis is more than respiration which sustain plant's growth and development but when respiration is more than photosynthesis plant's growth and development will undergo retardation. The higher night temperature that gives rise to increase in respiration leads to reduced net gain in form of grain yield due to loss in water, leaves potential and sudden shoot up of air temperature in early spring when wheat and other winter crops are at reproductive stage of their life cycle causing significant reduction in grain yield. It is therefore important to know the effect of temperature on the individual life and growth processes of crops in order to understand the effect on plants as a whole. The aim of this article is to review the impact of extreme temperature elevation on plant growth, development and crop yield.

\section{METHODOLOGY}

This paper was based on the intense review of published articles on plant growth, development and crop yield; factors affecting plant growth, development and crop yield; transpiration; impact of climate change on agriculture; and analyzing the impact of extreme temperature elevation using some mathematical equations relating parameters with each other either by direct formula, derived formula or by mathematical manipulation. Parameters such as stomatal opening and Stomatal Conductance, Vapor Pressure Deficit, Temperature, Photosynthesis, Yield, Transpiration, $\mathrm{CO}_{2}$ Concentration, Cuticle Resistance, Rubisco Activity and Electron Transportation, Leaf Water Stress and Leaf Water Potential are used in this study. Internet facility was employed for this research especially e-library to retrieve 
text books, journals, research papers etc. for an updated information on the topic from other researchers and related studies e.g. google alerts and google trends to track comprehensive search over lengthy period.

\section{DISCUSSION}

3.1 The Following Equations were Used in the Discussion

$$
\begin{aligned}
& \mathrm{VPD}=\left(1-\frac{\mathrm{RH}}{100}\right)\left(610.7 \times 10^{\left(\frac{7.5 \mathrm{~T}_{\mathrm{k}}}{237.3+\mathrm{T}_{\mathrm{k}}}\right)}\right) \text {. } \\
& \mathrm{G}_{\mathrm{s}}=\frac{\mathrm{T}}{\mathrm{VPD}} \\
& \mathrm{G}_{\mathrm{s}}=\left(\frac{273}{\mathrm{~T}+273}\right)\left(\frac{\mathrm{P}}{101.3}\right) \\
& \mathrm{G}_{\mathrm{s}}=\frac{k \mathrm{P}_{\mathrm{n}}(\mathrm{RH})}{\mathrm{C}_{\mathrm{s}}} \\
& P_{n}=\frac{G_{s}\left(C_{s}-C_{i}\right)}{1.6} \\
& \frac{\mathrm{C}_{\mathrm{i}}}{\mathrm{C}_{\mathrm{a}}}=\left[1-\frac{1.6}{\mathrm{k}(\mathrm{RH})}\right] \\
& \mathrm{C}_{\mathrm{i}}=\mathrm{C}_{\mathrm{a}}\left[1-\frac{1.6}{\mathrm{k}(\mathrm{RH})}\right] \\
& \mathrm{G}_{\mathrm{s}}=\left(\frac{1.6 \mathrm{P}_{\mathrm{n}}}{\mathrm{C}_{\mathrm{s}}}\right)\left(1+\frac{\mathrm{g}_{1}}{\sqrt{\mathrm{VPD}}}\right) \\
& \mathrm{w}_{\mathrm{j}}=\frac{\mathrm{J}_{\mathrm{lim}}\left(\mathrm{C}_{\mathrm{i}}-\Gamma_{*}\right)}{4\left(\mathrm{C}_{\mathrm{i}+} \Gamma_{*}\right)} \\
& \mathrm{G}_{\mathrm{s}}=\frac{1.6 \mathrm{P}_{\mathrm{n}}}{\mathrm{C}_{\mathrm{s}}-\mathrm{C}_{\mathrm{i}}} \\
& \mathrm{G}_{\mathrm{s}} \propto\left(1+\frac{\mathrm{g}_{\mathrm{i}}}{\sqrt{\mathrm{VPD}}}\right) \\
& \mathrm{G}_{\mathrm{S}} \propto \mathrm{P}_{\mathrm{n}} \\
& \mathrm{G}_{\mathrm{s}} \propto \frac{1}{\mathrm{C}_{\mathrm{s}}} \\
& \frac{\mathrm{Y}}{\mathrm{T}}=\frac{\mathrm{k}}{\mathrm{e}_{\mathrm{s}}-\mathrm{e}_{\mathrm{a}}}=\frac{\mathrm{k}}{\mathrm{VPD}} \\
& \mathrm{Y}=\mathrm{kG}_{\mathrm{s}} \\
& \mathrm{Y}=\frac{\mathrm{kT}}{\mathrm{g}_{\mathrm{i}}^{2}}\left[\frac{\mathrm{G}_{\mathrm{S}} \mathrm{C}_{\mathrm{i}}}{1.6 \mathrm{P}_{\mathrm{n}}}-1\right]^{2} \\
& \mathrm{G}_{\mathrm{s}}=100 \mathrm{kP} \mathrm{P}_{\mathrm{n}}\left[\frac{\left(1-\frac{\mathrm{VPD}}{\mathrm{SVP}}\right)}{\mathrm{C}_{\mathrm{s}}}\right] \\
& \mathrm{G}_{\mathrm{s}}=\mathrm{KT}_{\mathrm{k}}\left[\frac{\left(1-\frac{\mathrm{VPD}}{\mathrm{SVP}}\right)}{\mathrm{C}_{\mathrm{s}} \times \mathrm{VPD}}\right] \\
& G_{c}=\frac{E_{c}}{D} \times \frac{\rho G_{V}}{M_{W}} \frac{T_{k}}{3600} \times \frac{P_{a}}{T_{k} R} \\
& G_{c}=\frac{E_{c}}{D} \times \frac{\rho G_{V}}{M_{W}} \frac{T_{k}}{3600} \\
& \mathrm{G}_{\mathrm{S}}=\frac{\mathrm{Y}}{\mathrm{k}} \\
& \mathrm{Y}=\mathrm{R}_{\max } \times \frac{\mathrm{C}}{\mathrm{C}-\mathrm{K}_{\mathrm{c}}}+\mathrm{R}_{\text {int }} \\
& \mathrm{G}_{\mathrm{s}}=\beta\left(\mathrm{R}_{\max } \times \frac{\mathrm{C}}{\mathrm{C}-\mathrm{K}_{\mathrm{c}}}+\mathrm{R}_{\mathrm{int}}\right) \\
& \mathrm{G}_{\mathrm{s}}=\frac{\propto \mathrm{P}_{\mathrm{n}} \mathrm{e}^{-\left(\frac{\psi}{\mathrm{c}}\right)^{\mathrm{b}}}}{\left(\mathrm{C}_{\mathrm{s}}-\Gamma^{*}\right)\left(1+\frac{\mathrm{VPD}}{\mathrm{d}_{1}}\right)} \\
& \text { Rate of Transpiration }(\Gamma)=\frac{\psi_{\mathrm{L}}-\psi_{\mathrm{A}}}{\chi}=\frac{\Delta \psi_{\mathrm{LA}}}{\chi} \text {. } \\
& \mathrm{P}_{\mathrm{a}} \mathrm{V}=\mathrm{RT}_{\mathrm{k}} \\
& \mathrm{G}_{\mathrm{C}}=\frac{\mathrm{E}_{\mathrm{C}}}{\mathrm{D}} \times \frac{\mathrm{G}_{\mathrm{V}}}{\mathrm{V}^{2}} \times \frac{\mathrm{T}_{\mathrm{k}}}{3600} \\
& \mathrm{G}_{\mathrm{S}}=\frac{\mathrm{T}}{\mathrm{VPD}}=\frac{\omega}{\chi} \\
& \mathrm{G}_{\mathrm{s}}=\frac{\mathrm{Y}}{\mathrm{k}}=\frac{\omega}{\chi}
\end{aligned}
$$

Where, $\mathrm{T}_{\mathrm{k}}$ is Air Temperature, $\mathrm{P}$ is Atmospheric Pressure, VPD is Vapor Pressure Deficit, RH is Relative Humidity, T is Transpiration rate, $\mathrm{P}_{\mathrm{n}}$ is Photosynthesis, $\mathrm{C}_{\mathrm{s}}$ is $\mathrm{CO}_{2}$ Concentration at the leaf surface, $\mathrm{C}_{\mathrm{i}}$ is Intercellular (leaf internal) Carbon Dioxide Concentration, $\mathrm{g}_{1}$ is a speciesspecific parameter, $\mathrm{G}_{\mathrm{s}}$ is Stomatal Conductance, $\mathrm{k}$ and $\omega$ are species-Specific Constant, $w_{j}$ is Ribulose-1,5bisphosphate (RuBP) Regeneration limited rate of Photosynthesis, $\mathrm{J}_{\text {lim }}$ is light-limited rate of Electron Transport and $\Gamma_{*}$ is $\mathrm{CO}_{2}$ compensation point in the absence of non-photorespiration. $\mathrm{Y}$ is Yield Component (e.g. total above-ground biomass or seed production), $\mathrm{T}$ is Cumulative 
Actual Transpiration, $e_{s}$ is Saturated Vapor Pressure, $-e_{a}$ is the Actual Vapor Pressure that exist in the air, $\mathrm{k}$ is a constant with unit in milibars $* \mathrm{~g}$ (dry matter) $* \mathrm{~g}^{-1}$ (water). Note that $\mathrm{m}$ and $\mathrm{k}$ depend on Yield Component, Species, Photosynthesis Mechanism, and VPD. $\mathrm{P}_{\mathrm{a}}$ is Atmospheric
Pressure, $G_{V}$ is Gas Constant for Water Vapor, $G_{C}$ is Canopy Conductance, $\mathrm{M}_{\mathrm{W}}$ is Molecular Mass of Water, $\mathrm{R}$ is Gas Constant, $\chi$ is Leaf Cuticle Resistance.

3.2 Relationship Between Stomatal Conductance, Temperature and Vapor Pressure Deficit

In equation (1) Vapor pressure deficit increased as temperature increases. And from equation (8):

$$
\begin{aligned}
\mathrm{G}_{\mathrm{s}} & \propto\left(1+\frac{\mathrm{g}_{\mathrm{i}}}{\sqrt{\mathrm{VPD}}}\right) \ldots \\
\mathrm{G}_{\mathrm{s}} & \propto \mathrm{P}_{\mathrm{n}} \ldots \ldots \ldots \ldots \ldots \ldots \ldots \ldots \ldots \ldots \ldots \ldots \\
\mathrm{G}_{\mathrm{S}} & \propto \frac{1}{\mathrm{C}_{\mathrm{s}}} \ldots \ldots \ldots \ldots \ldots \ldots \\
\mathrm{Y} & =\frac{\mathrm{kT}}{\mathrm{g}_{\mathrm{i}}^{2}}\left[\frac{\mathrm{G}_{\mathrm{s}} \mathrm{C}_{\mathrm{i}}}{1.6 \mathrm{P}_{\mathrm{n}}}-1\right]^{2}
\end{aligned}
$$

From equation (2) Stomatal Conductance decreased as Vapor Pressure Deficit increases, this is an indication that Stomatal Conductance decreases with increase in temperature, as seen in equation (3).

Decrease in Stomatal Conductance $\left(G_{s}\right)$ reduced photosynthesis $\left(\mathrm{P}_{\mathrm{n}}\right)$ from equation (12) but increased intercellular system of the leaf from equation (13). The escalation of temperature and its associated VPD increases intercellular system of leaf $\mathrm{CO}_{2}$ concentration to impair photosynthesis because increasing $C_{s}$ decrease $\left(G_{s}\right)$. According to Baligar et al. (2008) in all three genotypes of cocoa, increased VPD reduced $P_{n}$, but the slight decrease in $\mathrm{G}_{\mathrm{S}}$ and the slight increase in $\mathrm{C}_{\mathrm{i}}$ or $\mathrm{C}_{\mathrm{s}}$ with increasing VPD were non-significant, while significant increase in VPD increased $\mathrm{E}$ (or $\mathrm{T}$ ) and this may have caused the reduction in $P_{n}$.

Increase in VPD coupled with reduced $G_{S}$ that decreased photosynthesis is an indirect negative impact of increasing temperature on Stomatal Conductance resulting into decrease in photosynthesis. According to Satoshi et al. (2015) decrease of canopy conductance in a high temperature treatment is more likely caused by increasing VPD than by increasing temperature.

Baligar et al. (2008) reported that increasing VPD decreases photosynthesis $\left(P_{n}\right)$ and according to Satoshi et al. (2015) increase in temperature reduced photosynthetic rate by reducing Stomatal Conductance. Also, that Stomatal Conductance was shown to have negative relationship with VPD. As Baligar et al. (2008) stated that $\mathrm{C}_{\mathrm{s}}$ and $\mathrm{C}_{\mathrm{i}}$ increase with increase in VPD, so it can be said that the reduction in photosynthetic rate is just the consequence (or outcome) of reduced Stomatal Conductance with increased VPD due to temperature escalation i.e. the major photosynthetic impairment is the Stomatal Conductance reduction (stomatal closure) which is from the consequence of increase in temperature and its associated VPD.

Where there is reduction in Stomatal Conductance and photosynthesis, and increased concentration of $\mathrm{CO}_{2}$ in the internal system of the leaf, it might be thought of low yield. Baligar et al. (2008) reported further that, the usually small response of $G_{s}$ to VPD could limit the ability of cocoa to growth where VPD is high. Balasimha et al. (1991) found that photosynthesis in cocoa was highest during the period of low evaporation demand (low VPD) and that diurnal patterns of these parameters indicate transient midday (period of high temperature water deficits which reduced photosynthesis i.e. high temperature depressed photosynthetic rate (Oh-e et al., 2007)). According to Urban et al. (2014), plant exposed to saturated irradiance, high temperature and high VPD may have afternoon depression of photosynthesis, particularly due to stomatal closure and that the enhancement in the photosynthetic capacity in assimilation causes a rise in cultivation at $20 / 15^{\circ} \mathrm{C}$, which is better than a cultivation at $30 / 25^{\circ} \mathrm{C}$ (Ushio et al., 2008). Tsuno and Yamaguchi (1987) clarified that hightemperature depress the photosynthetic rate through the reduction in root activity. Therefore, increase in temperature indirectly has negative impact through increase in VPD to reduce Stomatal Conductance and photosynthetic rate causing impairments in the growth, development and cocoa plant yield.

\subsection{The Effect of Increasing Temperature on Crop Yield can be Illustrated as Follows}

In the simple form of equation (1), it is seen that there is an increase in temperature with simultaneously increase in VPD and eventually decreased yield.

$\frac{\mathrm{Y}}{\mathrm{T}}=\frac{\mathrm{k}}{\mathrm{e}_{\mathrm{s}}-\mathrm{e}_{\mathrm{a}}}=\frac{\mathrm{k}}{\mathrm{VPD}}$

And manipulations of equations (2 and 14) gives equation:

$\mathrm{Y}=\mathrm{kG}_{\mathrm{s}}$
$\mathrm{Y}$ is Yield Component (e.g. total above-ground biomass or seed production), $\mathrm{T}$ is Cumulative Actual Transpiration, $\mathrm{e}_{\mathrm{s}}$ is Saturated Vapor Pressure, $-\mathrm{e}_{\mathrm{a}}$ is the Actual Vapor Pressure that exist in the air, $\mathrm{k}$ is a constant with unit in milibars $* \mathrm{~g}$ (dry matter) $* \mathrm{~g}^{-1}$ (water). Note that $\mathrm{m}$ and $\mathrm{k}$ depend on Yield Component, Species, Photosynthesis Mechanism and VPD. 
Equation (1 and 14) were manipulated to get, the yield equation in term of Stomatal Conductance, intercellular $\mathrm{CO}_{2}$ Concentration, Photosynthesis and Transpiration.

$\mathrm{Y}=\frac{\mathrm{kT}}{\mathrm{g}_{\mathrm{i}}^{2}}\left[\frac{\mathrm{G}_{\mathrm{s}} \mathrm{C}_{\mathrm{i}}}{1.6 \mathrm{P}_{\mathrm{n}}}-1\right]^{2}$

It is seen that increasing the temperature, increased the VPD and that Stomatal Conductance $\left(\mathrm{G}_{\mathrm{s}}\right)$ is inversely proportional to VPD from equation (2) and Yield (Y) is inversely proportional to VPD from equation (14), while Yield $(\mathrm{Y})$ is proportional to $\mathrm{G}_{\mathrm{s}}$ in equation (15 and 16$)$. Increasing VPD with increase in temperature reduces $G_{s}$ and consequently reduced yield. It is also seen that $G_{s} \propto P_{n}$ from equations $(4,8$ and 12$)$ that photosynthetic rate decreases as Stomatal Conductance decreases which might affect yield negatively. According to White and Mark (2002) the rate of growth of roots, stems and leaves depend on the rate of photosynthesis, which in turn depends on light, temperature, moisture and $\mathrm{CO}_{2}$. It is seen that increasing temperature and its associate (VPD) can cause reduction in Stomatal Conductance to reduced photosynthetic rate; if then photosynthesis could be reduced with increasing temperature via stomatal closure or reduced Stomatal Conductance, then it is expected that there can be impairment in the growth rate of roots, stem and leaves which might lead to reduction in the crop yield. Lafta and James (1995) reported that activity of potato tuber enzymes was reduced by the elevated temperature; and that potato tuber growth was reduced under high temperatures in both cultivars. It was also stated in the introduction that heat stress (or extreme temperature elevation) alters carbohydrate partitioning in potato plants from tubers to shoots, and reduces overall plants yield. Oh-e et al. (2007) reported that the relation between brown rice yield and mean air-temperature during 20 days after heading (flowering) showed that the brown rice yield declined when mean air-temperature exceeds $28^{\circ} \mathrm{C}$. Hatfield (2016) soybean crop yield decreased with increasing temperatures, and maize yield decreased $8.3 \%$ per $1{ }^{\circ} \mathrm{C}$ rise without any complicating effect due to water stress, while the review by Hatfield and Prueger (2015) summarized that rising temperatures increase the rate of phonological development, leading to a smaller plant and reduced productivity because of the shortened growth cycle. Analysis revealed that daily minimum temperature will increase more rapidly than daily maximum temperatures leading to the increase in the daily maximum temperature and a greater likelihood of extreme events, and these changes could have detrimental effect on grain yield (Meehl et al., 2007). Maize pollen viability decreases with exposure to temperature above $35^{\circ} \mathrm{C}$ (Herrero and Johnson, 1980). The major impact of warmer temperature was during reproductive stage of development and in all cases grain yield in maize was significantly reduced by as much as $80-$ $90 \%$ from a normal temperature regime (Hatfield and Prueger 2015). Rice (Orzya sativa) shows a similar temperature to maize because pollen viability and production declines as day time maximum temperature $\mathrm{T}_{\max }$ exceeds $33^{\circ} \mathrm{C}$ and ceases when $\mathrm{T}_{\max }$ exceeds $40^{\circ} \mathrm{C}$ (Kim et al., 1996). Crops grown under a temperature regime with increased average temperatures would have negative effects on plant productivity due to the effect on the grainfilling period (Hatfield, 2016). In fact, the projected air temperature increasing throughout the remainder of the $21^{\text {st }}$ century suggests that grain yields will continue to decrease for the major crops because of increased temperature stress on all major crops (Hatfield and Prueger, 2015). Increased temperature will affect the physiological processes necessary for crop growth and development, and ultimately crop yields are most likely to drop over the present level. Climatic anomalies will play an important role in increasing the uncertainties in crop production, and that productivity of wheat and other crop species falls markedly at high temperatures (Rasul et al., 2011).

\subsection{Carbon Dioxide Concentration Increases with Increasing Temperature or VPD}

Manipulating equation (1 and 4$)$ to get:

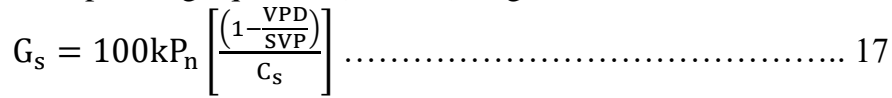

Ideally, photosynthesis increases with increasing Temperature $\left(\mathrm{P}_{\mathrm{n}} \propto \mathrm{T}_{\mathrm{k}}\right)$; photosynthesis also increases with increasing Stomatal Conductance $\left(P_{n} \propto G_{s}\right)$; Stomatal Conductance decreases with increasing VPD. $\left(G_{s} \propto \frac{1}{V P D}\right)$ and then $\left(P_{n} \propto \frac{1}{V P D}\right)$ and finally $\left(\mathrm{P}_{\mathrm{n}} \propto \frac{\mathrm{T}_{\mathrm{k}}}{\mathrm{VPD}}\right)$. Equation (17) now becomes:

$\mathrm{G}_{\mathrm{s}}=\mathrm{KT}_{\mathrm{k}}\left[\frac{\left(1-\frac{\mathrm{VPD}}{\mathrm{SVP}}\right)}{\mathrm{C}_{\mathrm{s}} \times \mathrm{VPD}}\right]$

$\mathrm{K}$ is a constant (or is other parameters that are kept constant) that can influence Stomatal Conductance positively or negatively. Also remember equation (1) that VPD $\propto \mathrm{T}_{\mathrm{k}}$.

Equation (18) is in line with equation gotten from Kostner et al. (1996) and Braun et al. (2010) on canopy conductance estimations.

$G_{c}=\frac{E_{c}}{D} \times \frac{\rho G_{V}}{M_{W}} \frac{T_{k}}{3600} \times \frac{P_{a}}{T_{k} \mathbf{R}}$

Where $\mathbf{G}_{\mathbf{c}}$ is the canopy conductance for vapor $\left(\mathrm{mol} \mathrm{m}^{-2} \mathrm{~s}\right.$

$\left.{ }^{1}\right), \boldsymbol{E}_{\boldsymbol{c}}$ or $\boldsymbol{T}$ is the canopy transpiration rate, D is VPD $\left(\mathrm{k} \boldsymbol{P}_{\boldsymbol{a}}\right), \boldsymbol{\rho}$ is the density of water $\left(998 \mathrm{Kg} \mathrm{m}^{-3}\right), \boldsymbol{G}_{\boldsymbol{V}}$ is the gas constant for water vapor $\left(0.462 \mathrm{~m}^{3} \mathrm{kP}_{\boldsymbol{a}} \mathrm{kg}^{-1} \mathrm{~K}^{-1}\right), \boldsymbol{T}_{\boldsymbol{k}}$ is the air temperature on the absolute temperature scale $(\mathrm{K}), \boldsymbol{M}_{\boldsymbol{W}}$ is the molecular mass of water $\left(18.02 \mathrm{~g} \mathrm{~mol}^{-1}\right), 3600$ is obtained by conversion of hours to seconds, $\boldsymbol{P}_{\boldsymbol{a}}$ is the atmospheric pressure $\left(101.3 \mathrm{k} \boldsymbol{P}_{\boldsymbol{a}}\right)$, and $\mathrm{R}$ is the gas constant 
$\left(8.31 \mathrm{~J} \mathrm{~mol}^{-1} \mathrm{~K}^{-1}\right)$. The third component involving $\boldsymbol{P}_{\boldsymbol{a}}, \boldsymbol{T}_{\boldsymbol{k}}$ and $\mathrm{R}$ is obtained by the conversion of canopy conductance $G_{c}=\frac{E_{c}}{D} \times \frac{\rho G_{V}}{M_{W}} \frac{T_{k}}{3600}$

As temperature is increasing, VPD increases also; to reduce the nominator in equation (18) and to also increase the denominator from equations (18 and 19) leading to decrease in $\boldsymbol{G}_{\boldsymbol{s}}$; the reduction in the value of $\boldsymbol{G}_{\boldsymbol{s}}$ will increase the accumulation of $\boldsymbol{C}_{\boldsymbol{i}}$ and $\boldsymbol{C}_{\boldsymbol{s}}$ in equation (18) leading to further stomatal closure or reduced Stomatal Conductance. i.e. the stomatal closure or decrease in Stomatal Conductance from the consequence of increasing temperature will elevate $\boldsymbol{C}_{\boldsymbol{s}}$ and $\boldsymbol{C}_{\boldsymbol{i}}$ which will further enhance stomatal closure and reduction in Stomatal Conductance. According to Kirschbaum and McMillan (2018), although increased $\mathrm{CO}_{2}$ generally leads to some stomatal closure in most plant, and that Stomatal Conductance is typically reduced by about $40 \%$ under double $\mathrm{CO}_{2}$ and that the $\mathrm{CO}_{2}$ limitation of photosynthesis

According to Baligar et al. (2008) increasing $\boldsymbol{C}_{\boldsymbol{s}}$ increased $\boldsymbol{C}_{\boldsymbol{i}}$ and high concentration of $\boldsymbol{C}_{\boldsymbol{s}}$ and $\boldsymbol{C}_{\boldsymbol{i}}$ are expected at extreme temperature and VPD especially at the intercellular system of the leaf. The effect of increase in $\boldsymbol{C}_{\boldsymbol{i}}$ has more internal damage on the leaf and on the photosynthesis than the $\boldsymbol{C}_{\boldsymbol{s}}$ due to greenhouse gases activity. So, the impact of increase in $\boldsymbol{C}_{\boldsymbol{i}}$ on $\boldsymbol{P}_{n}$ and $\boldsymbol{G}_{\boldsymbol{s}}$ should be considered as a factor to be reckoned with. Satoshi et al. (2015) made it clear that Stomatal Conductance was found to have a negative relationship with $\boldsymbol{C O}_{2}$ concentration and that the response of Stomatal Conductance to $\mathbf{C O}_{2}$ concentration is associated with the intercellular $\boldsymbol{C O}_{2}\left(\right.$ or $\left.\boldsymbol{C}_{\boldsymbol{i}}\right)$ rather than with the $\boldsymbol{C O}_{2}\left(\right.$ or $\left.\boldsymbol{C}_{s}\right)$ concentration at the leaf surface or in the stomatal pores.

Leaf temperature elevation is expected because of $\boldsymbol{C}_{\boldsymbol{s}}$ and $\boldsymbol{C}_{\boldsymbol{i}}$ greenhouse effect. According to Kirschbaum and McMillan (2018) climate change is an increase in global warming, and the extent of the temperature increase depends on the magnitude of increases in greenhouse gases e.g. $\mathrm{CO}_{2}$ concentration. In addition to radiative forcing by elevated $\mathrm{CO}_{2}$, partial stomatal closure in response to elevated $\mathrm{CO}_{2}$ reduces transpiration surface cooling and

3.5 Impact of VPD and Carbon Dioxide Concentration on Yield Equations ( 2 and 14 ) by manipulations will give:

It is seen in equation (18) that increasing leaf surface $\boldsymbol{C}_{\boldsymbol{s}}$ or intercellular $\boldsymbol{C}_{\boldsymbol{i}}$ concentration and the increase in VPD are consequences of increasing temperature that enhanced stomatal closure or reductions in Stomatal Conductance $\boldsymbol{Y}=\boldsymbol{R}_{\text {max }} \times \frac{C}{C-K_{c}}+\boldsymbol{R}_{\text {int }}$

Where $\mathrm{Y}$ is relative response of photosynthesis, biomass yield, or seed yield; $\boldsymbol{R}_{\max }$ is asymptotic upper limit for Y from baseline $\boldsymbol{R}_{\text {int }} ; \mathrm{C}$ is carbon dioxide concentration (ppm); $\boldsymbol{K}_{\boldsymbol{c}}$ is Apparent Michaelis constant(ppm); while $\boldsymbol{R}_{\boldsymbol{i n t}}$ is $\mathrm{Y}$-axis intercept for zero $\mathrm{C}$. units from $\mathrm{mm} \mathrm{s}^{-1}$ to $\mathrm{m}^{-2} \mathrm{~s}^{-1}$ and with conversion to $\mathrm{m}^{-2} \mathrm{~s}^{-1}$. The equation remains as:

generally increases with increasing temperature, so that the $\mathrm{CO}_{2}$ responsiveness of photosynthesis is expected to be greater for sites from warmer than cooler location The increase in $\mathrm{CO}_{2}$ concentration, which is considered as the main cause of the global warming, may decrease Stomatal Conductance. High temperatures will also signal stomata to close, increasing the water loss from the leaf, with less water available; guard cells can become flaccid (soft or less turgor) and close (Sterling, 2004). Another effect of high temperatures is that respiration rates rise above photosynthetic rate causing an increase of $\mathrm{CO}_{2}$ in the leaves; high internal $\mathrm{CO}_{2}$ will cause stomata to close or it will cause reduction in Stomatal Conductance as well (Sterling, 2004).

thereby adds to global warming and that increases the $\mathrm{CO}_{2}$ concentration above ambient, increasing the temperature optimum for photosynthesis (Crafts-Brande and Salvucci, 2000). High concentration of $\boldsymbol{C}_{\boldsymbol{s}}$ and $\boldsymbol{C}_{\boldsymbol{i}}$ will increase leaf surface and internal temperature.

In equations (18, 19 and 20), $\boldsymbol{T}_{\boldsymbol{k}}$ is proportional to $\boldsymbol{G}_{\boldsymbol{s}}$ or $\boldsymbol{G}_{\boldsymbol{c}}$ i.e. Stomatal Conductance increases with temperature, but the Stomatal Conductance is inversely proportional to VPD, increasing VPD with a decreased $\boldsymbol{G}_{\boldsymbol{s}}$ or $\boldsymbol{G}_{\boldsymbol{c}}$. But VPD increases with increasing temperature. Increasing temperature can be seen as an indirect climate parameter hidden under its ability to enhance increase in VPD to influence Stomatal Conductance. Even from equation (19), with $\mathrm{m}^{-2} \mathrm{~s}^{-1}$ unit, the canopy conductance $\left(\boldsymbol{G}_{\boldsymbol{c}}\right)$ is independent of $\boldsymbol{T}_{\boldsymbol{k}} \quad\left(\boldsymbol{G}_{\boldsymbol{C}}=\frac{\boldsymbol{E}_{\boldsymbol{c}}}{\boldsymbol{D}} \times \frac{\boldsymbol{\rho} \boldsymbol{G}_{V}}{\boldsymbol{M}_{W}} \times \mathbf{0 . 0 0 0 2 7}\right)$, but depend on VPD or D, as according to Satoshi et al. (2015) increasing temperature has no direct effect on canopy conductance and that the response of Stomatal Conductance at slight increase in temperature is associated with an increase in VPD rather than an increase in temperature.

$$
G_{s}=\frac{Y}{k}
$$

$\left(\boldsymbol{G}_{\boldsymbol{s}}\right)$; and also in equation (20), leading to impairment of yield $(\mathrm{Y})$ in equation $(21)$.

The above statement can be confirmed with the following equation:

The $\boldsymbol{K}_{\boldsymbol{c}}$ can also be called substrate $\boldsymbol{C}_{\boldsymbol{i}}$ that was photosynthetically utilized. The higher the substrate, the more the system is photosynthetically inclined i.e. the more the $\mathbf{C}_{\boldsymbol{i}}$ carbon dioxide concentration utilized or assimilated, it leads to an increase in the photosynthesis, transpiration and yield. The lower the substrate, the more the system is photosynthetically declined i.e. the less the $\boldsymbol{C}_{\boldsymbol{i}}$ carbon 
dioxide concentration utilized or assimilated, it leads to an enhanced accumulation of $\boldsymbol{C}_{\boldsymbol{n}}$ carbon dioxide concentration both on the leaf surface $\left(\boldsymbol{C}_{\boldsymbol{s}}\right)$ and in the intercellular system of the leaf $\left(\boldsymbol{C}_{\boldsymbol{i}}\right)$, this then raise the leaf Equation (21 and 22) through manipulation can be expressed as:

$\boldsymbol{G}_{\boldsymbol{s}}=\boldsymbol{\beta}\left(R_{\max } \times \frac{\boldsymbol{C}}{\boldsymbol{C}-\boldsymbol{K}_{\boldsymbol{c}}}+\boldsymbol{R}_{\text {int }}\right)$

The Stomatal Conductance increases as substrate $\left(\boldsymbol{K}_{\boldsymbol{c}}\right)$ increases, leading to higher photosynthesis and transpiration rate. But the Stomatal Conductance decreases as substrate $\left(\boldsymbol{K}_{\boldsymbol{c}}\right)$ decreases, leading to decline in photosynthesis and transpiration rate. The stomatal closure or declined in Stomatal Conductance, photosynthesis and transpiration will further enhance $\mathrm{CO}_{2}$ concentration on and in the leaf as a consequence of increasing temperature i.e. From equation 21, 22 and 23, decline in Stomatal Conductance, also means decline in photosynthesis, transpiration and most especially decline in the biomass and yield. This is the effect of increase in temperature that consequently makes $\boldsymbol{C}$ to be decreased yield. Since transpiration and photosynthesis have positive correlation coefficient with production (Zakariyya and Prawoto, 2015), then decrease in photosynthesis will decrease production.

This reduction in photosynthesis will further enhance the concentration of $\boldsymbol{C}_{\boldsymbol{s}}$ and $\boldsymbol{C}_{\boldsymbol{i}}$ in the leaf surface and intercellular system respectively, consequently leading to further reduced $\boldsymbol{G}_{\boldsymbol{s}}$ and $\boldsymbol{P}_{\boldsymbol{n}}$ which will eventually impair temperature due to greenhouse effect and consequently leading to the impairment of photosynthesis, transpiration and yield.

plant growth and yield (Ushio et al., 2008). Thus, high temperature (HT) leads to a rapid leaf expansion, and results in a higher initial growth rate. However, because potential photosynthesis was not enhanced, it is concluded that HT does not suit the growth of the assimilation shoots that rose before shoot bending (Ushio et al., 2008). Equation (22) is also an indication that yield is indirectly dependent on temperature, as temperature enhances increase in concentration of $\mathrm{CO}_{2}$ on the leaf surface and intercellular leaf system. The major factor that seems to influence photosynthesis, transpiration and yield in equation (22) is the $\mathrm{CO}_{2}$ substrate. According to Kirschbaum and McMillan (2018), reductions in Stomatal Conductance driven by increase in atmospheric $\mathrm{CO}_{2}$ are likely to be of greater importance in determining changes in transpiration rates (and photosynthesis) than the temperature and associated VPD. The negative effect of increasing $\mathrm{CO}_{2}$ concentration on Stomatal Conductance and yield can be regarded as an indirect effect of increasing temperature and associated VPD.

\subsection{Transpiration, Leaf Water Potential and Leaf Water Deficit/Leaf Water Stress}

From the Ball-Berry-Leuning model combined with a Weibull sensitivity to leaf potential (Anderegg et al., 2017).

$\boldsymbol{G}_{s}=\frac{\propto \boldsymbol{P}_{n} e^{-\left(\frac{\psi}{c}\right)^{b}}}{\left(C_{s}-\Gamma^{*}\right)\left(1+\frac{V P D}{d_{1}}\right)}$

Where $\boldsymbol{\psi}$ is the leaf water potential, c, b, $\propto, \boldsymbol{d}_{\mathbf{1}}$ are species specific parameters and $\boldsymbol{\Gamma}^{*}$ is the $\mathrm{CO}_{2}$ compensation point.

Rate of Transpiration $(\Gamma)=\frac{\psi_{L}-\psi_{A}}{\chi}=\frac{\Delta \psi_{L A}}{\chi}$

Where, $\boldsymbol{\psi}_{S}$ is Soil Water Potential, $\boldsymbol{\psi}_{\boldsymbol{A}}$ is Atmospheric Air Water Potential, $\Delta \boldsymbol{\psi}_{\boldsymbol{S A}}$ is Water Potential Gradient between Soil and Air Atmospheric Water Moisture, $\boldsymbol{\psi}_{\boldsymbol{L}}$ is Leaf Water Potential, $\Delta \boldsymbol{\psi}_{L A}$ is Water Potential Gradient between Leaf and Atmosphere, $\boldsymbol{\chi}$ is Cuticle Resistance.

From equation (24), $\boldsymbol{G}_{\boldsymbol{s}}$ will decrease as VPD increases, this is an evidence of increased temperature. In equation (2), $\boldsymbol{G}_{\boldsymbol{s}} \propto \boldsymbol{T}$ (transpiration), so VPD at elevated value decrease $\boldsymbol{G}_{s}$ to reduce transpiration. Ideally, transpiration increases with increasing temperature or VPD, but the leaf will be losing water as transpiration increases with increasing temperature, so the continuous losing of water in leaf during transpiration will lead to leaf water deficit especially when crops cannot take up sufficient water from soil to meet up with the crop water needed; a deficit occur (McKenzie, 2017) or leaf water stress consequently leads to reduction of leaf water potential $\left(\boldsymbol{\psi}_{L}\right)$, which according to equation (25) transpiration is de-enhanced, de-valued or impaired i.e. transpiration decreases. The actual cause of reduction in transpiration is not increase in temperature but decrease in leaf water potential due to leaf water loss as transpiration increases with temperature. In equation (24), decrease in $\left(\boldsymbol{\psi}_{\boldsymbol{L}}\right)$ de-enhanced, de-value or impaired $\boldsymbol{G}_{\boldsymbol{s}}$ i.e. Stomatal Conductance decreases. At a very-high reduced value of $\boldsymbol{\psi}_{L}$, there will be possibility of stomatal closure to conserved water, leading to sharp reduction in transpiration and Stomatal Conductance as temperature extremely increases, and this leads to photosynthetic impairment as a consequence of reduced Stomatal Conductance; in equations (19 and 20), decrease in density ( $\boldsymbol{\rho}$ ) decrease Stomatal Conductance $\left(\boldsymbol{G}_{\boldsymbol{S}} \boldsymbol{o r} \boldsymbol{G}_{\boldsymbol{c}}\right)$. Potential gradient per volume of water lost through transpiration decreases as transpiration increases, and density decreases along with decrease in Leaf Water Potential resulting into stomatal closure or decrease in Stomatal Conductance. According to Putra et al. (2012) there were linear relationship between stomatal width, Stomatal Conductance and transpiration rate, and wider stomata has shown to result in higher conductance and transpiration rate. And also, according to Gimenez .C et al. (2005) Stomatal Conductance is related to leaf $\boldsymbol{\psi}_{\boldsymbol{L}}$ by feedback processes, and reduction in Leaf Water Potential can induce stomatal closure, resulting in lowered Stomatal Conductance (Gimenez .C et al., 2005). 
The negative impact of increasing leaf water loss on the Stomatal Conductance in equation (19) can be seen through

$P_{a} V=R T_{k}$

Where, $\mathrm{V}$ is the Volume water loss through transpiration or Volume of leaf water loss. Through manipulating equations (19 and 26), this will be gotten:

$G_{C}=\frac{E_{C}}{D} \times \frac{G_{V}}{V^{2}} \times \frac{T_{k}}{3600}$

The increase in the volume of leaf water loss as transpiration is increasing leads to leaf water deficit and reduction in Leaf Water Potential. This will eventually reduce the stomatal or canopy conductance. Looking at equation (27) critically, it can be seen that increases in temperature and transpiration indeed should increase Stomatal Conductance, but because increasing the temperature leads to simultaneous increase in the D (or VPD); and increasing transpiration will enhance volume (V) of water loss through the leaf, so the effect of increase in leaf water loss as transpiration increases reduced the Stomatal Conductance. It can also be seen that the determinants of Stomatal Conductance impairments are not based on increasing temperature and transpiration, but on the increase in the VPD and Volume (V) of leaf water lost. The volume of water loss through transpiration is equivalent to volume of leaf water loss. The leaf water deficit (or stress) is proportional to the volume of leaf water loss, while the leaf water potential is inversely proportional to the volume of leaf water loss.

Equations (14, 16 and 19) illustrates how increase in transpiration can determine yield with increase in temperature. In equation (2), Stomatal Conductance $\left(\boldsymbol{G}_{\boldsymbol{s}}\right)$ is proportional to Transpiration $(\boldsymbol{T})$; in equation $(14,16$ and $19)$, Yield $(\boldsymbol{Y})$ is proportional to transpiration $(\boldsymbol{T})$; and with the manipulation of equations (2 and 14), Yield $(\boldsymbol{Y})$ is proportional to Stomatal Conductance $\left(\boldsymbol{G}_{\boldsymbol{s}}\right)$. This is an evidence that when transpiration and Stomatal Conductance increase, yield increase. The major problem is when leaf

According to Kirschbaum and McMillan (2018), reducing Stomatal Conductance in response to plant stress such as high temperature and VPD, leaf water stress or leaf water deficit, very low leaf water potential and increasing $\mathrm{CO}_{2}$ concentration, reduces transpiration rates. Also, increasing $\mathrm{CO}_{2}$ concentration reduces transpiration rates through stomatal closure, and increasing temperature and a rising increase in $\mathrm{CO}_{2}$ concentration have opposing effects on transpiration. Although increasing assimilation rate acts as one factor to maintain higher Stomatal Conductance, a direct response to increasing $\mathrm{CO}_{2}$ concentration has an overriding effect because these increase in $\mathrm{CO}_{2}$ concentration also cause Stomatal Conductance to decrease sharply. Even though transpiration tend to increase with increasing temperature but the increasing $\mathrm{CO}_{2}$ concentration seriously negate the positive association between the increasing temperature and transpiration. Reduction in transpiration rates are even greater if there is photosynthesis downward acclimation which is simply an indication that the transpiration-depressing effect of elevated $\mathrm{CO}_{2}$ concentration generally dominate over the transpirationenhancing effect of increasing temperature. Therefore, it

the introduction of gas equation: water loss through increasing transpiration is not adequately compensated by the water transported from the root. The large volume of water loss will enhance stomatal closure and de-enhance transpiration leading to poor yield when water transportation from root to leaf is inadequate. Lack of rainfall and extreme evaporation of water from the soil with temperature elevation can lead to inadequate water intake by the root, leading to little amount of water transported to the leaf, which may not be able to compensate the amount of water volume lost from the leaf through transpiration.

Factors that can negatively impact Stomatal Conductance or stomatal opening will also negatively impact transpiration, photosynthetic system and yield. Increasing VPD as temperature is increasing reduced Stomatal Conductance (see equations: 2, 3, 8, 11, 17, 18, 19 and 24). Decrease in Leaf Water Potential also reduced Stomatal Conductance (see equation 24) and increasing $\mathrm{CO}_{2}$ concentration reduces Stomatal Conductance (see equations 4, 8, 13, 16, 17, 18, 23 and 24). As the volume of leaf water loss is increasing, Stomatal Conductance will decrease (see equation 27). Decreasing Stomatal Conductance will in turn reduce transpiration and photosynthetic processes (see equations 2, $4,8,10,12,16,17,19$ and 24). This decrease in Stomatal Conductance (that decreases photosynthesis and transpiration) will eventually negatively impact yield (see equations $2,4,12,14, \mathbf{1 5}^{*}, 16,17,19, \mathbf{2 1}^{*}$ and 24$)$. $*$ is a simple relationship between stomatal conductance $\left(G_{s}\right)$ and yield $(Y)$.

would be wise to say that reductions in Stomatal Conductance driven by increases in atmospheric $\mathrm{CO}_{2}$ concentration are likely to be of greater importance in determining changes in transpiration rates than increases in temperature and associated VPD. If only temperature would have been the only factor where other factors are kept constant; transpiration could be enhanced (transpiration increase strongly with increasing temperature), but increasing temperature and associated VPD increases the $\mathrm{CO}_{2}$ concentration by stomatal closure, thereby reducing the Stomatal Conductance and allowing accumulation of $\mathrm{CO}_{2}$ on leaf surface and intercellular system of the leaf. So, changes in the $\mathrm{CO}_{2}$ concentration could be the best factor to access transpiration rate alteration. Generally, stomatal closure under elevated $\mathrm{CO}_{2}$ has a quantitative larger effect in reducing transpiration rates than the effect of increasing temperature in increasing transpiration rates.

Transpiration rate is inversely proportional to plant/leaf Cuticle Resistance (i.e. $\boldsymbol{T} \propto \frac{\mathbf{1}}{\chi}$, see equation 25). Plants from hot, dry climates have thicker cuticles than plants 
from cool, moist climate, and leaves that develop under direct sunlight will have thicker cuticles than leaves that develop under shade conditions (Sterling, 2004). This is an indication that increasing temperature increases cuticle thickness and drastically reduces respiration. Stomatal Resistance is reciprocal of Stomatal Conductance i.e. $\left(\boldsymbol{G}_{\boldsymbol{S}} \propto \frac{\mathbf{1}}{\chi}\right)$. At extreme temperature elevation, Cuticle Resistance or Stomatal Resistance increases to reduce Stomatal Conductance, and consequently reduce $G_{s}=\frac{T}{V P D}=\frac{\omega}{\chi}$

Stomatal Resistance increases with increasing VPD as temperature increases, leading to impairment of Stomatal Conductance, transpiration and impacting photosynthesis negatively. This will lead to poor crop yield (Y). The Cuticle (or Stomatal Resistance) is the waxy layer present on all above-ground tissue (or above the epidermis layer of leaf) of a plant, and serves (or acts) as a barrier to water movement out of a leaf; cuticle being waxy, will show repulsion of water and attraction by water vapor (Sterling, 2004; Supriya, 2020). The thicker the cuticle layer on a leaf

$$
\mathrm{C}_{6} \mathrm{H}_{12} \mathrm{O}_{6}+6 \mathrm{O}_{2} \leftrightarrow 6 \mathrm{CO}_{2}+6 \mathrm{H}_{2} \mathrm{O}
$$

Inadequate water movement out of the leaf will hinder transpiration and photosynthesis which are necessarily needed for plant growth, development and crop yield.

It has been stated above that:

$G_{s}=\frac{Y}{k}=\frac{\omega}{\chi}$

k and $\omega$ are constants. As temperature and its associated VPD increases, the Stomatal Resistance increases to decrease yield (Y).

\subsection{Effect of Increasing Temperature on Rubisco Activation/Activity}

From equation (9), as internal leaf (intercellular) $\mathrm{CO}_{2}$ concentration $\left(\boldsymbol{C}_{\boldsymbol{i}}\right)$ increases, the denominator will increase by factor $\boldsymbol{\Gamma}$ to reduce $\boldsymbol{w}_{\boldsymbol{j}}$, and the electron transportation decreases with increase in temperature leading to decrease in Rubisco activity i.e. increasing temperature increase $\boldsymbol{C}_{\boldsymbol{i}}$, decrease electron transportation and consequently decrease $\boldsymbol{w}_{\boldsymbol{j}}$ that drive photosynthetic rate. According to Perdomo et al. (2017) in addition to Rubisco activation that was impaired at high temperature coupled with increased $\boldsymbol{C}_{\boldsymbol{i}}$, moderately high temperature can also inhibit or decrease electron transportation activity that is of positive correlation with Rubisco activity, inhibit/decrease adenosine triphosphate (ATP) synthesis causing the enzyme to become inactive and as well inhibit/decrease RuBP regeneration. So, Rubisco activase $\left(\boldsymbol{R}_{\boldsymbol{c} \boldsymbol{a}}\right)$ based on equation (9), became a primary cause of the decrease in photosynthesis in response to elevated temperature. According to Feller et al. (1998) high temperatures inhibit

\section{CONCLUSION}

Temperature elevation may have the following effects on plant: increased transpiration, increased water loss, increased leaf water deficit or increased leaf water stress, reduced leaf water potential, reduced stomatal opening or Stomatal Conductance and causing accumulation of $\mathrm{CO}_{2}$ concentration $\mathrm{C}_{\mathrm{s}}$ and $\mathrm{C}_{\mathrm{i}}$ on the leaf surface and in the photosynthetic $\mathrm{CO}_{2}$ fixation and Rubisco activity is an evidence of diffusive limitations which are consequence of stomatal closure (i.e. decreased Stomatal Conductance, $\mathbf{G}_{\mathbf{s}}$ ), and increased leaf resistance to $\mathrm{CO}_{2}$ transport from the atmosphere to the site of carboxylation (i.e. decrease mesophyll conductance). Also, as temperature increases further above the thermal optimum and reaches nonphysiological conditions, photosynthesis may be increasingly limited due to impairment of the physical integrity of electron transport components of the photosynthetic apparatus (Crafts-Brande and Salvucci, 2000); and Rubisco activase ( $\mathbf{R}_{\mathbf{c a}}$ ) becomes the primary cause of the decreases in photosynthesis in response to elevated temperature (Crafts-Brande and Salvucci, 2000). According to Perdomo et al. (2017), the activity of $\mathbf{R}_{\mathbf{c a}}$ is extremely thermally sensitive and that this enzyme becomes inactive, decreasing the rate of net $\mathrm{CO}_{2}$ assimilation at moderately high temperature.

intercellular (internal) system of the leaf respectively; this further leads to stomatal closure or reduced Stomatal Conductance and consequently impaired plant in transpiration and photosynthesis with reduction in Rubisco activity which at the end hinders plant growth, development and crop yield. 
It can be concluded that the negative impact of extreme temperature elevation on plant growth, development and crop yield is an indirect impact because increasing temperature generally increase Stomatal Conductance and transpiration, and increasing temperature also normally increase water VPD, consequently leading to a reduced Stomatal Conductance. According to Satoshi et al. (2015) increasing temperature has no direct effect on canopy conductance and the response of Stomatal Conductance at slight increase in temperature is associated with an increase in VPD rather than because of an increase in temperature. Also according to Kirschbaum and McMillan (2018)

\section{REFERENCES}

[1] Anderegg W.R.L., Wolf A., Arango-Velez A., Choat B., Chmura D.J., Jansen S., Kolb T., Li S., Meinzer F., Pita P., Resco de Dios V., Sperry J.S, Wolfe B.T., Pacala S. (2017): Plant Water Potential Improves Prediction of Empirical Stomatal Models. Doi: 10.1371/journal.pone.0185481

[2] Balasimha D., Daniel E.V., Bhat P.G. (1991). Influence of Environmental Factors on Photosynthesis in Cocoa Trees. Agric For Meteorol 55(12):15-21. Doi: 10.1016/0168-1923(91)90019-M

[3] Baligar V.C, Bunce J.A, Machado R.C.R, Elson M.K. (2008) Photosynthetic Photon Flux Density, Carbon Dioxide Concentration, and Vapor Pressure Deficit Effects on Photosynthesis in Cacao Seedlings. Photosynthetica 46 (2): 216-221.

[4] Braun S., Schindler C., Leuzinger S. (2010). Use of Sap Flow Measurements to validate Stomatal Functions for Mature Beech (Fagus Sylvatical) in View of Ozone Uptake calculations. Environmental Pollution, 158, 2954-2963.

[5] Crafts-Brandner S.J. and Salvucci M.E. (2000). Rubisco Activase Constrains the Photosynthetic Potential of Leaves at High Temperature and $\mathrm{CO}_{2}$. Proc. Natl. Acad. Sci. U.S. A 97, 1343013435|PNAS|vol.97|no.24. Doi.10.1073/pnas.230451497

[6] Dyer M.H. (2020). Does Weather Affect Plant Growth: Effect of Temperature On Plants https://www.gardeningknowhow.com/plantproblems/environm.ental/temperature-on- plants.htm

[7] Feller U., Crafts-Brandner S.J., Salvucci M.E. (1998). Moderately High Temperature Inhibit Ribulose-1,5-Bisphosphate Carboxylase/Oxygenase, (Rubisco) Activase-Mediated Activation of Rubisco: Plant Phsiol. (1998) 116:539-546. Doi: 10.1104/pp.116.2.539

[8] Gimenez C ... Thompson R. B (2005) Plant-Water Relations: In Encyclopedia of Soil in Environment

[9] Hatfield J.L. (2016). Increased Temperatures Have Dramatic Effects on Growth and Grain Yield of Three Maize Hybrids. Agricultural \& Environmental Letters Research Letter. Doi: 10.2134/ael2015.10.006

[10] Hatfield J.L., Prueger J.H. (2015). Weather and Climate Extremes: Temperature Extremes: Effect on Plant Growth and Development. www.elsevier.com/locate.wace 10, 4-10. Doi: 10.1016/j.wace.2015.08.001

[11] Herrero M.P and Johnson R.R. (1980). High Temperature Stress and Pollen viability in Maize Crop. Sci 20, 796-800

[12] Kim H.Y., Horie J.H.Y., Horie T., Nakagawa H., Wada K. (1996). Effects of elevated $\mathrm{CO}_{2}$ concentration and high temperature on growth and yield of rice. II. The effect of yield and its component of Akihikari rice. Jpn. J. Crop Sci. 65, 644-651.J.L.

[13] Kirschbaum M.U.F and McMillan A.M.S. (2018). Warming and Elevated $\mathrm{CO}_{2}$ Have Opposing Influences on Transpiration which is more Important. Current Forestry Reports, 4:51-71 Doi: 10/1007/s40725-018-0073-8

[14] Kostner B., Biron P., Siegworth R., Granier A. (1996). Estimates Water Vapor Flux and Canopy Conductance of Scots Pine at a tree Level Utilizing Different Xylem Sap Flow Methods. Theorectical and Applied Climatology, 53, 105-113.

[15] Lafta A.M. and James L.H. (1995). Effect of Hugh Temperature on Plant Growth and Carbohydrate-Metabolism in Potato. Plant Physiol (1995) 109: 637-643. Published by www.plantphysiol.org American Society of Plant Biologists.

[16] McKenzie R.H. (2017). Understanding the effect of Sunlight, Temperature and Precipitation.

[17] Meehl G.A., Stocker T.F., Collins W.D., Gaye A.J., Gregory J.M., Kitoh A., Knutti R., Murphy J.M., Noda A., Raper S.C.B., Watterson J.G., Weaver A.J., Zhao Z. (2007). Global Climate Projections. In: Solomon S., stomatal closure (decrease in Stomatal Conductance) under elevated $\mathrm{CO}_{2}$ has a quantitatively larger effect in reducing transpiration rates than the effect of increasing temperature in ceasing transpiration rate, that reductions in Stomatal Conductance driven by increases in atmospheric $\mathrm{CO}_{2}$ are likely to be of greater importance in determining changes in transpiration rates than increases in temperature and associated VPD. Anderegg et al. (2017) stated that Stomatal Conductance is a simple function of photosynthetic rate, atmospheric $\mathrm{CO}_{2}$ concentration, and either relative humidity or VPD.

Qin D., Manning M., Chen Z., Marquis M., Averyt K.B., Tignor M., Miller H.L. (Eds.), Cambridge University Press, Cambridge, U.K. and New York, NY.

[18] Oh-e I., Saitoh K., Kuroda T. (2007). Effects of High Temperature on Growth, Yield and Dry-Matter Production of Rice Grown in the Paddy Field, Plant Production Science, 10:4, 412-422, Doi: 10.1626/pps.10.412

[19] Ojo A.D. and Sadiq I. (2010). Effect of climate change on cocoa yield' Journal of Sustainable Development in Africa. Vol. 12 No 1.

[20] Osei E.M. (2017). Climate Variability and Cocoa Production: The Implications of Micro Adaptation Measures On Cocoa Farmers' Income

[21] Perdomo J.A, Capo-silva E.,Galmes J. (2017). Rubisco and Rubisco Activase Play an Important Role in the Biochemical Limitation of Photosynthesis in Rice, Wheat, and Maize under High Temperature and Water Deficit. Front Plant Sci.3:490. Doi.10.3389/fpls.207.00490

[22] Powell J.P. and Reinhard S (2016). Measuring the Effects of Extreme Weather events on Yields. Weather and Climate Extreme

[23] Putra E.T.S., Zakaria W., Abdullah N.A.P., Saleh G.B. (2012). Stomatal Morphology, Conductance and Transpiration of Musa sp. cv. Rastali in Relation to Magnesium, Boron and Silicon Availability. American Journal of Plant Physiology, 7: 84-96. Doi: 10.3923/ajpp.2012.84.96 URL: https://scialert.net/abstract/?doi=ajpp.2012.84.96

[24] Rasul G.1, Chaudhry Q.Z., Mahmood A., Hyder K.W. (2011). Effect of Temperature Rise on Crop Growth and Productivity. Pakistan Journal of Meteorology Vol. 8, Issue 15.

[25] Satoshi N., Tacarrindua R.P., Keiichiro N., Koki H., Tatsuhiko S. (2015). Evaluation of the Effects of Increasing Temperature on the Transpiration rate and Canopy Conductance of Soybean by Using the Sap Flow Method. Journal of Agricultural Meteorology 71 (2): 98-105.

[26] Sterling T.M. (2004). Transpiration - Water Movement through Plants. Department of Entomology, Plant Pathology and Weed Science, New Mexico State University. Journal of Natural Resources and Life Sciences Education, Volume 34, Issue 1. Doi: 10.2134/jnrlse.2005.0123. http://croptechnology.unl.edu

[27] Supriya N. (2020) Transpiration in Plants https://biologyreader.com/transpiration-in-plants.html

[28] Tsuno Y. and Yamaguchi T. (1987). Relationships between respiratory rate of root and temperature modulated photosynthesis in rice plant and the factors concerning the respiratory rate of root. Jpn. J. Crop Sci. 56:536$546 * *$

[29] Urban O., Klem K., Holisova P., Sigut L., Sprtova M., TeslovaNavratilova P., Zitova M., Spunda V., Marek M.V., Grace J. (2014): Impact of Elevated $\mathrm{CO}_{2}$ Concentration on Dynamics of Leaf Photosynthesis in Fagus sylvatical is Modulated by Sky Conditions. Environment Pollution 185: 271-280.

[30] Ushio A., Mae T., Makino A. (2008). Effects of temperature on photosynthesis and plant growth in the assimilation shoots of a rose. Soil Science and Plant Nutrition 54, 253. Japanese Society of Soil Science and Plant Nutrition Blackwell Publishing Ltd. Doi: 10.1111/j.17470765.2007.00234.x

[31] Went P.M. (1953). The Effect of Temperature on Plant Growth. Annual Review of Plant Physiology. Vol. 4: 347-462. Pp.04.060153002023. Doi: 10.1146/annurev.

[32] White D.H. and Mark H.S. (2002). Encyclopedia of Life Support-EOLSS: Soils, Plant Growth and Crop Production - Vol. I - Climate and its Effects on Crop Productivity and Management.

[33] Zakariyya F. and Prawoto A. (2015). Stomatal Conductance and Chlorophyll Characteristics and their Relationship with Yield of some Cocoa Clones under Tectona grandis sp., and Cassia surattensis. Pelita 
Paul O. Jaiyeola ${ }^{1,2}$, Funmilola A. Oluwafemi ${ }^{2,3}$, Abdullahi Ayegba ${ }^{2,4}$, Irene E. Benibo ${ }^{1,2}$

${ }^{1}$ National Centre for Remote Sensing (NCRS), Jos, Nigeria.

${ }^{2}$ National Space Research and Development Agency (NASRDA), Abuja, Nigeria.

${ }^{3}$ Federal University Oye-Ekiti (FUOYE), Oye-Ekiti, Ekiti-State, Nigeria.

${ }^{4}$ Federal University Technology Akure (FUTA), Ondo State, Nigeria. 